Journal of History Culture and Art Research

Revue des Recherches en Histoire Culture et Art

مجلة البحوث التاريخية و الثقافية و الفنية
Vol. 2, No. 2, June 2013

Copyright (C) Karabuk University

http://kutaksam.karabuk.edu.tr/index.php

Özel Sayı/Special Issue

(English Studies)

DOI: 10.7596/taksad.v2i2.249

\title{
Prospective Teacher Concerns: A Comparative Study of Departments of English Language Teaching and Language and Literature
}

\author{
M. Naci KAYAOĞLU, M. Kerem KOBUL, Şakire ERBAY*
}

\begin{abstract}
Language teachers in Turkey do not take a standard pre-service education as graduates of English Language Teaching (ELT), linguistics, and translation departments all end up with language teaching profession and this, in turn, results in different teaching needs and concerns. The researchers argue that these different concerns may be one of the underlying causes of chronic language education problems in Turkey, in that Turkish Ministry of National Education does not take into consideration the comparative picture of practicing teachers and composes curricula, teaching materials, and compulsory one-shot professional development activities that all reflect "one size fits all" ideology. Therefore, determining the needs and concerns of pre-service language teachers is of vital importance. The current study has arisen from Griffith's (2012) call for more larger-scale studies on teacher concerns across different contexts via triangulation. The researchers aim at not only investigating teacher concerns but also painting a much detailed comparative picture between ELT and linguistics department prospective teachers. The researchers target convenience sampling, in the full knowledge that this group will not represent the whole population. However, this type of nonprobability sampling can serve well when it is easy to gather much informative data. Building
\end{abstract}

\footnotetext{
* Karadeniz Technical University, Faculty of Letters.
} 
on the recent work of Griffiths (2012), the researchers have modified and extended the existing measurement tool of Griffiths (2012) to investigate the issue much deeper and compensate the caveats. They adapted her instrument and asked the participants to add their thoughts as well as deciding their concern level. The results are mainly in line with the referred study in terms of the rating and frequency. The study reveals that there are some differences between the concerns of ELT department students and language and literature department students. While prospective teachers studying at the ELTdepartment were found to be highly concerned about technology, their counterparts studying at the langauge and literature department were not interested in the issue. The study also reveals that despite EIL's large space in the literature (Cogo, 2012; Sowden, 2012), it was not found as a major concern for the prospective teachers. Methodology was also the least rated concern for the prospective teachers at both departments on the contrary to the well-accepted literature.

Keywords: Teacher concerns, prospective teacher, ELT, language and literature.

\section{Introduction}

Researching teacher beliefs, concerns and perceptions has gained much room in the related literature as their beliefs are seen vital to understand their classroom applications. Donaghue (2003) best explains this urgency when she writes that uncovering teachers' beliefs, concerns, and assumptions are necessary to encourage teachers to start change process by reflecting on their practices. As these beliefs are believed to shape teaching practices, their sources should be revealed to encourage the practitioner to think about what they have been doing in their own classrooms. This, in turn, could encourage teachers to strengthen their pedagogy, stay up to date and employ new techniques. In addition, beliefs are important as "there is often a great difference in teacher development between input (from the trainer/expert), uptake (elements which participants find interesting and consider transferable to classrooms, i.e. which match their own theory), and output (what is actually implemented in the participants' classes)" (p.344). Exploring the sources of this paradox could serve well for consistency among these three elements, and ultimately smooth the way for teacher development.

\section{Review of Literature}

The impetus for the popularity of this issue comes from Fuller's (1969) seminal work, which has become a foundation stone for further studies of teaching concerns. Fuller explains the teaching concerns development with three stages: self-concern, task-related concerns, and concerns over a teacher's impact. The teachers who are at the beginning of their teaching careers are believed to be in the first stage and have some concerns regarding classroom 
management, students, parents, school administrators, to name just a few. Later, the teachers start to develop task-related concerns, which are about curriculum, class preparation, time management, grading, lesson planning, and administrative responsibilities. In the last stage, teachers start to be interested in their impacts. They start to question whether they could meet students' needs regarding their academic, social, and emotional growth (cited in Boz \& Boz, 2010, p. 281; Çelik, 2008, p. 98).

Inspired by Fuller's (1969) study, a great number of researchers from various contexts have conducted studies to explore teachers' beliefs, concerns, and assumptions (Donaghue, 2003; De Jong, Ahtee, Goodwin, 1999; Guillaume \& Rudney, 1993; Kyriacou \& Stephens, 1999; Mau, 1997; Swennen, Jörg \& Korthagen, 2004).The issue attracted so much attention that some researchers have developed instruments to elicit teachers' beliefs. For example, inspired by Kelly's (1969) the Repertory Grid Technique (cited in Donaghue, 2003, p. 346), which is based on reflective teaching process, Donaghue (2003) developed an activity conducted via a set of cards on which there are elements from Kelly's (1969) grid. The participants are encouraged to reflect on teacher belief constructs which serve well as reflection prompts.

One of the preliminary studies on the concerns of particularly prospective teachers is Mau's (1997) study which mainly investigates the teaching concerns of 48 prospective teachers from different majors such as science, maths, English etc. during their initial practicum experience in terms of the things that create some kind of mild anxiety on them or their worries rather than the things they consider to be important or their priorities. The study mainly demonstrates that the highest concern for the prospective teachers after their first classroom teaching experience were "maintaining appropriate class control" and "meeting pupil needs of unmotivated students and students with different levels of achievement" (p. 63) respectively.

Swennen, Jörg, \& Korthagen (2004) looked for a change in the concerns of first year students in Dutch context in which "the first year is meant for appraisal and selection of students" (p. 268) to continue their study to be a teacher. What is appealing in the study is that the students had a tendency to slowly give up their concern about themselves and to developed teaching-related concerns. However, it is somewhat surprising that the students' concerns did not develop much during the first year.

One of the recent studies on teacher concern belongs to Griffiths (2012), who conducted a small-scale survey with forty six in-service teachers studying for a Master degree in ELT at a private university in Istanbul, Turkey. Her study showed that the teachers were mostly concerned about classroom issues, content. Technology and professional accountability followed these concerns. Although methodology and English as an International Language (EIL) have been frequently discussed in the related literature, they 
caused the least concern mean rating among the in-service teachers. She concludes that with all their concerns, needs, worries, teachers are human, and their primary concerns, i.e. classroom issues, should be taken into consideration and they should be provided with support and training.

The issue has also attracted much attention in Turkish context, and following Fuller's (1969) work, Turkish researchers have tried to complete the angle. For example, Cabaroglu (2012) conducted a study with eleven prospective teachers studying at the English language teaching department of a university in Turkey. The study mainly investigates the prospective teachers' perceptions of classroom management. However, it revealed that the participants had a wide range of concerns both before and after teaching practice such as survival issues, teaching situations as well as students themselves.

Another teacher concern study from Turkish context belongs to Boz and Boz (2010) who draw attention to the prospective teachers' concerns about their teaching and their sense of efficacy by their study carried out with three hundred and thirty-nine prospective teachers of secondary science and mathematics education departments of two universities in Turkey. Their study reveals that self-related concerns of fifth-year students were found to be much lower than the self concerns of the third-year students. With the own words of the researchers, this "supports Fuller's (1969) model, which indicated that teachers' self-survival concerns decrease with experience" (p. 288).

Moreover, a study undertaken by Yaylı and Hasırcı (2009) with four hundred thirty two prospective Turkish language teachers tries to give an account of the effects of the year of study at the university, gender or "schooling shift (daytime or evening)" (p. 519) on their concerns. The findings of the study reveal that while the year of study at the university and gender have significant effects on the types of concerns (self, task, and impact) in Fuller's (1969) classification, schooling shift, which is peculiar to Turkey context, has no significant effect.

As summarizes above, there are a number of studies on teacher concern, yet they are not enough as teacher beliefs, concerns, and assumptions that form the basis of their application are context specific (Karataş, 2010). Studying teacher concerns is of vital importance because "beliefs ... guide teachers in their practice" (Donaghue, 2003, p. 344). Çelik (2008) also draws attention to the concerns of prospective teacher as he points out "concerns can help promote a better understanding of the transition period from student teacher to (beginning) teacher" (p. 98). Thus, thanks to the results of these context specific studies, teachers could be effectively guided at the very beginning of their teaching career (Boz \& Boz, 2010). Moreover, as Griffiths (2012) states, more parallel studies are needed "to help a bridge between the ivory tower of the university (where it all went so well) and the 
good ideas we read in journals, and the actualities of the classroom" (p. 470-471). Lastly, similar studies are expected to contribute to research methodology.

\section{Methodology}

The aim of this small-scale cross-sectional survey is to investigate concerns of prospective teachers and compare the findings of the participants from ELT and language and literature departments. A survey may serve well to explore attitudes, preferences and beliefs on a one-shot basis (Cohen, Manion, \& Morrison, 2007; Robson, 1993). The present study is descriptive as it aims to describe and compare the prospective teachers' concerns from two separate departments and two state universities.

The student and teacher participants of the present study were chosen via convenience sampling from two mid-size state universities from the east and northeast parts of Turkey. The researchers are aware of the limitation of this type of opportunity sampling in that representative findings cannot be gained (Robson, 1993; Cohen et al., 2007); however, easy access to participants, saving time and cost could enable the researchers to draw a detailed picture of teacher concerns.

The study aimed 54 English Language and Literature and 132 ELT students. However, as participation was on voluntary basis, the data was gathered from 19 Language and Literature Department students attending 4th grade (18 F \& $1 \mathrm{M}$ ) (One participant not wanting to be a teacher was eliminated) and 107 ELT students attending 4th grade (79 F, 23 M, 5 missing). Their ages are between 22-24, and they are all non-native speakers of English

An adapted version of English Language Teacher Concerns Questionnaire (Griffiths, 2012) was used to gather the survey data. It is a five-point Likert scale (1=unconcerned to $5=$ strongly concerned). At the very beginning of the instrument, the participants were asked whether they aimed at working as an English language teacher, and the negative ones were eliminated as the aim is to learn teacher concerns. In addition, comment parts were included in order to contextualise the quantitative findings by adding a qualitative dimension to the survey and investigate the precise nature of participants' concern. There were six concern areas in the original version, namely methodology, content, technology, professional accountability, classroom issues, and EIL. As the researchers believe that teacher development is a very important concern area, they added it as a seventh concern area. In addition, they made the nature of EIL much clearer via adding the concept English as a Lingua Franca as it takes much room in the related literature (see for example, Breiteneder, 2009; Canagarajah, 2007; Cogo, 2012; Jenkins, 2009; Seidlhofer, 2004, 2005; Sowden, 2012).

SPSS Version 16.00 was used to find out the mean ratings of the results. Later, a content analysis of the questionnaires was conducted. Having organised the questionnaires, the researchers determined codes under each concern area. Later, they constructed category 
groups for the codes and the frequency of each code was counted via tally mark. The main features of the data analysis were summarized (Cohen et al., 2007; Krippendorff, 2004). In order to contextualise the quantitative and qualitative findings, the researchers illuminated the teaching concerns of both parties by quoting representative excerpts taken from participants' accounts.

\section{Findings}

The findings are presented by study groups below.

\section{Concern Areas of the Participants from Language and Literature Department}

Table 1. Concern Mean Ratings of the Participants from Language and Literature Department

\begin{tabular}{l|c}
\multicolumn{1}{c|}{ ISSUE } & MEAN RATING \\
\hline CONTENT & 4.33 \\
\hline CLASSROOM ISSUES & 4.10 \\
\hline PROFESSIONAL DEVELOPMENT & 3.82 \\
\hline METHODOLOGY & 3.75 \\
\hline TECHNOLOGY & 3.50 \\
\hline EIL/ELF & 3.33 \\
\hline PROFESSIONAL ACCOUNTABILITY & 3.14 \\
\hline
\end{tabular}

As Table 1 summarizes above, content caused the highest mean rating with 4.33 among the participants from the language and literature department. Classroom issues follow content with the mean rating 4.10. The concern areas professional development and methodology cause similar mean ratings, 3.82 and 3.75 respectively. Technology comes after methodology with mean rating 3.50. EIL/ELF and professional accountability were found to be the least frequently stated concern areas for the participants, with mean ratings 3.33 and 3.14 respectively.

In order to contextualise the quantitative findings above, the researchers conducted a qualitative analysis. The codes regarding content were categorised under the category "the quality of content". The participants stated that content that the teacher brings to the classroom should be important $(\mathrm{N}=1)$, determined by collaborating with students and conducting a need analysis $(\mathrm{N}=1)$, suitable for students' level $(\mathrm{N}=1)$, and interesting $(\mathrm{N}=1)$. In addition, one participant highlighted the importance of the content knowledge of the 
teacher. The following excerpt taken form one of the participants can best summarize what is important in content for prospective teachers:

"Content plays an important role in English language learning. The level of the students and content should be appropriate to each other. Thus, teacher reach his/ her aim and take the fruits of his/her learning. " (Participant 3)

Classroom issues got the second highest mean rating following content among the participants from the language and literature departments. When the qualitative data was analyzed, the following codes were associated with classroom issues: classroom management $(\mathrm{N}=5)$ interaction patterns $(\mathrm{N}=1)$, enjoyable classroom activities $(\mathrm{N}=1)$, taking individual differences into consideration $(\mathrm{N}=1)$, and time management $(\mathrm{N}=1)$. The participants stated that they had questions in their minds whether they would be able to handle the problems in their classrooms teeming with students with individual differences. Participant 3 expresses this common concern as follows:

"Classroom management is one of the main problem in classroom issues. In the classroom, each student has different level of understanding so teacher should find an appropriate material for all students to reach them "(Participant 3)

Professional development was the third most frequently stated concern area. When the qualitative findings were analyzed, the codes were grouped as the reasons for professional development: to keep pace with teaching field $(\mathrm{N}=2)$, to teach effectively and easily $(\mathrm{N}=1)$, and to gain students' trust $(\mathrm{N}=1)$. The following two excerpts can show how one participant attaches importance to growth while the other one sees it as context specific, and writes that the institution in which one works determines the need for professional development:

"I think, professional development influences both teachers and students. If a teacher develops himself professionally, his knowledge increases and he gets experience that is the most important thing in a job. Moreover, if a teacher develops himself professionally confident of students on the teacher also increases." (Participant 15)

"It depends on where you will be an English teacher. If I was an English teacher in primary school I would not develop myself because I had to depend on the schedule the school that give me." (Participant 3)

Although methodology is regarded as the basics of one's teaching in most degree programs at faculties, the prospective teachers from the language and literature department did not attach great importance to it. It was associated with the aim to serve well for learner differences $(\mathrm{N}=3)$ : 
"We learned the methodology of teaching an English for example how we can prepare a lesson teaching and which materials we can use in a classroom. As an example we have to know the level of students and prepare the activity according to their levels" (Participant 5)

The qualitative findings regarding technology were analyzed and the codes were categorised as the reasons for technology: to enable effective teaching and learning $(\mathrm{N}=3)$, to increase motivation and attention $(\mathrm{N}=2)$, to serve well for different learner types $(\mathrm{N}=1)$, to provide various authentic materials and activities $(\mathrm{N}=1)$, and to keep up with today's pace of technological improvements $(\mathrm{N}=1)$. One participant was found to be anxious about the fact that technological advancements might result in the spread of incorrect information:

"Technology can be both beneficial and harmful for students, because without checking something from the books students might have dilemma which information is true." (Participant 3)

One of the least frequently stated concerns are is English as a Lingua Franca. Although the concept has much room in the related literature recently, it was not an important concern area among the participants. ELF was associated with undeniable English spread in various domains $(\mathrm{N}=1)$, and communicative function of English $(\mathrm{N}=1)$. Furthermore while one participant stated that $\mathrm{s} / \mathrm{he}$ had no idea about the concept, one was found to be neutral because of not using ELF: "I am neutral for ELF as I have never used English as a Lingua Franca" (Participant 15).

Lastly, the least important concern area for the participants from the language and literature department was found to be professional accountability/transparency. The participants were seen not to be familiar with the term and they associated it with teaching ability. They thought that professional accountability was necessary because it enhances communication with the teacher $(\mathrm{N}=1)$.

\section{Concern Areas of the Participants from English Language Teaching Department}

Table 2. Concern Mean Ratings of Participants from ELT Department

\begin{tabular}{l|c}
\multicolumn{1}{c|}{ ISSUE } & MEAN RATING \\
\hline TECHNOLOGY & 4.52 \\
\hline PROFESSIONAL DEVELOPMENT & 4.50 \\
\hline CONTENT & 4.41 \\
\hline CLASSROOM ISSUES & 4.40 \\
\hline METHODOLOGY & 4.33 \\
\hline PROFESSIONAL ACCOUNTABILITY & 3.76 \\
\hline EIL/ELF & 3,47 \\
\hline
\end{tabular}


As Table 2 summarizes above, technology was caused the highest mean rating (4.52) among the prospective teachers form the ELT department while it was not a serious concern area for the participants from the language and literature department. Professional development got nearly the same mean rating with technology, 4.50. Similarly, content and classroom issues caused approximately the same mean ratings, 4.41, and 4.40 respectively. Methodology with the mean rating 4.33 was the third area from the last. Similar to the findings regarding language and literature department, ELT department participants were found to be least concerned about professional accountability and EIL/ELF, with mean ratings 3.76 and 3.47 respectively.

Contrary to the participants from the language and literature department, ELT department students thought that technology was crucial for them. The content analysis of their comments indicates the following benefits of technology: effective teaching and learning $(\mathrm{N}=41)$, increasing motivation and attention $(\mathrm{N}=18)$, serving well for different learner types $(\mathrm{N}=9)$, saving time $(\mathrm{N}=9)$, keeping up with today's pace of technological improvements $(\mathrm{N}=9)$, providing various authentic materials and activities $(\mathrm{N}=8)$, less cost $(\mathrm{N}=1)$, and helping teachers develop their own materials $(\mathrm{N}=1)$. Participant 102 best summarizes the importance of technology for teachers as follows:

"Technologic devices will make easier to learn for students. It is important because it provides visuality and sounds. Technologic devices will make learning more enjoyable and what students learn will be more enjoyable and what students learn will be more permanent" (Participant 102)

Professional development was an important concern area for the prospective teachers from ELT department. They found it necessary to to keep pace with teaching field $(\mathrm{N}=18)$, to teach effectively and easily ( $\mathrm{N}=6)$, to gain students' trust $(\mathrm{N}=2)$, and to close the gap between the teacher and students $(\mathrm{N}=1)$. The following participant explains the function of professional development as follows:

"Teachers should be open to new learnings and new developments, both scientific and technological developments. They should be eager to develop themselves in almost every areas of fields" (Participant 57)

Content was also important for the prospective teachers and the analysis of their comments resulted in the category of content features as follows: planned $(\mathrm{N}=8)$, suitable for students' level $(\mathrm{N}=6)$, interesting $(\mathrm{N}=5)$, related to daily life $(\mathrm{N}=4)$, and determined by collaborating with students and conducting a need analysis $(\mathrm{N}=3)$. In addition, 5 participants emphasized the importance of content knowledge of the teacher while 3 attracted the attention to content-based instruction. Participant 123 lists the features of content as follows: 
"Content is one of the most important elements of teaching. Your content must be suitable firstly for students' levels and needs and then it should contain interesting things to attract students." (Participant 123)

When it comes to classroom issues, the participants touched the following issues:

Dealing with individual differences $(\mathrm{N}=24)$, creating encouraging and easy classroom atmosphere $(\mathrm{N}=10)$, using various teaching techniques and materials $(\mathrm{N}=8)$, listening to students' problems and helping them solve them $(\mathrm{N}=7)$, classroom management $(\mathrm{N}=4)$, tolerance for mistakes $(\mathrm{N}=1)$, and interaction patterns $(\mathrm{N}=1)$ :

"In teaching classroom issues can be defined as the atmosphere of classroom, studentstudent interaction. If it's taken into consideration during the teaching process, it will affect teaching positively/ magnificiently" (Participant 90).

Methodology was a concern area with a low mean rating. The participants stated that methodology results in effective teaching $(\mathrm{N}=23)$, serves well for learner differences $(\mathrm{N}=16)$, makes learning enjoyable and easy $(\mathrm{N}=8)$, forms the theoretical/knowledge base of teaching $(\mathrm{N}=4)$, helps the teacher avoid possible problems $(\mathrm{N}=2)$, and helps classroom management $(\mathrm{N}=1)$. Participant 105 expresses the importance of methodology as follows:

"Teaching approaches and methods shapes greatly the way the language is learnt. Without methods our teaching shouldn't have scientific base. Methods are also important guidelines for language teachers." (Participant 105)

Similar to the findings regarding the language and literature department, it was found that the prospective teachers form ELT department were not interested in professional accountability. Yet, they saw it necessary to help students feel safe and comfortable $(\mathrm{N}=2)$, to increase trust in teacher $(\mathrm{N}=1)$, to enhance student motivation $(\mathrm{N}=1)$, to enhance communication with the teacher $(\mathrm{N}=1)$, to promotes students' understanding the teacher well $(\mathrm{N}=1)$, to encourage students respect the teacher $(\mathrm{N}=1)$, and to enhances teacher's selfconfidence $(\mathrm{N}=1)$. Participant 47 best illuminates the exact nature of professional accountability as follows:

"Students should know what the teachers are doing and why they are doing what they do. Therefore, in the aspects teachers should be careful about their acts, behaviours in the classroom. If there are uncertanities in the classroom than students don't be comfortable." (Participant 47)

Although EIL/ELF is a very popular issue in the related literature, prospective teachers were found not to be interested in the issue. 38 participants stated that they were not familiar with the concept. EIL was associated with undeniable English spread in various domains $(\mathrm{N}=17)$, communicative function of English $(\mathrm{N}=4)$, job opportunities $(\mathrm{N}=1)$, local culture 
$(\mathrm{N}=1)$, different accents $(\mathrm{N}=1)$, and street language $(\mathrm{N}=2)$. The following participant reflects the concept as follows:

Today, all around the world English is a lingua franca. It is the common language used for communication, education, politics, and diplomacy. As lingua franca it affects all world and people. (participant, 47)

\section{Discussion}

As far as the seven concern areas are considered, the prospective teachers of English Language Teaching and Language and Literature departments have some variations in their concerns though the importance order of the concerns are roughly the same except one or two items. Contrary to expectations, at the top of the different concern areas there lays technology. While ELT graduate candidates were highly concerned about technology, literature department students were not interested in the issue. This could be attributed to technology-related or technology-driven courses/issues in education faculties such as Computer Assisted Language Learning/ Teaching that raise student's awareness towards the integration of technology into classroom. Moreover, this difference could have also been linked to digital natives and digital immigrants dichotomy (Prensky, 2001) when compared with the participants of the Griffiths' (2012) who are older than these prospective teachers "who are native to the Internet and the digital world" (Flynt \& Brozo, 2010, p.526) if it weren't for the participants from language and literature department who are already digital natives as well.

As another so-called important concern area, methodology caused no serious concern for both parties although the participants agreed with the argument of Larsen-Freeman (2000) that exposure to methods helps teachers "become clearer about why they do what they do" (p. vi). Although methodology courses at the ELT departments of universities of Turkey have been highly approved and well-accepted, and increased (Kırkgöz, 2005) especially after "1997 educational reform" (Kırkgöz, 2007, p. 177) by program developers, it is astonishing for the researchers to find out that it is not that well-appreciated concern area for the participants.

While classroom issues aroused quite a high level of concern among the participants attending literature department, it was not a serious concern for ELT participants. The available recent literature (Boz \& Boz, 2010; Cabaroglu, 2012; Griffiths, 2012) suggests that prospective teachers are deemed, thus, accepted to be concerned with the classroom issues, which Fuller (1969) coined as "self-concerns" stage, in that teachers are concerned more about issues such as classroom management and what other people might think about their teaching etc. However, the findings of this study, which corroborate Griffiths' findings, clearly reveal that prospective teacher participants from ELT department are not much concerned with classroom issues. This may be attributed to the fact that literature department 
graduates need teaching pedagogy courses to be a good teacher while ELT department students have high self-efficacy beliefs (Bandura, 1997; Cakiroglu, Cakiroglu, \& Boone 2005; Lin, Gorrell, \& Taylor, 2002) in themselves.

Despite EIL's large space in the literature (Cogo, 2012; Sowden, 2012) it was not a major concern for the pre-service teachers. However, this finding corroborates previous research of Griffiths (2012) who found that EIL was the least rated concern. This may stem from either some of the participants were not familiar with the concept or their negligence as they have much urgent needs regarding their own specific context.

Professional accountability also received low rating for concern for both parties. However, the answerability of all teacher practices by documentation and reporting their procedures is crucial for a healthy relationship between the teacher and students, which could result in a good classroom atmosphere and accomplishment. Awareness activities towards the importance of explaining the rationale behind one's practices are urgently needed.

\section{Conclusion}

This study aimed at investigating the concerns of prospective English language teachers studying not only at English language teaching departments of education faculties but also at language and literature departments of faculty of letters with the best intentions of the researchers to suggest practical implications for the everlasting foreign language education problems in Turkey. Moreover, the researchers aim at not only investigating teacher concerns but also depicting a detailed comparative picture of prospective teachers studying at ELT and language and linguistics department.

The results enable the researchers conclude that prospective teachers are deeply interested in issues such as content, classroom issues, professional development, and technology. Therefore, they need to be guided and given support and training regarding these survival issues when they start the teaching profession. In addition, much earlier, i.e. during pre-service teaching, these common concern areas could be offered as elective courses, and prospective teachers could be permitted freedom to improve themselves in whichever area they need and want. Furthermore, similar surveys could suggest a course of action for the Ministry of National Education so as to draw a general picture of teachers' concern areas rather than hold seminar, workshops or conferences that are determined by the authority. Lastly, it is evident that "many teacher concerns with respect to pedagogical issues remain inconclusive, unsolved, or unaddressed by SLA research" and "it is clear that SLA research and language pedagogy in many respects have their own concerns and agendas" (De Graaff \& Housen, 2009, p. 746), for improvement it is of vital importance that not only prospective teachers should also be encouraged to research their own practice by extensive action research projects (Wyatt, 2011) but also the prospective and/ or in-service teachers' concerns and thoughts should be taken into consideration while designing or improving any program. 


\section{References}

Bandura, A. (1997). Self-efficacy: The exercise of control. New York, NY: Freeman

Boz, Y., \& Boz, N. (2010). The nature of the relationship between teaching concerns and sense of efficacy. European Journal of Teacher Education, 33(3), 279-291.

Breiteneder, A. (2009). English as a lingua franca in Europe: an empirical perspective. World Englishes, 28(2), 256-69.

Cabaroğlu, N. (2012). Prospectıve EFLteachers' perceptions of classroom management and misbehaviour. Cukurova University Faculty of Education Journal, 41(1), 117-132.

Cakiroglu, J., Cakiroglu, E. \& W.J. Boone. (2005). Pre-service teacher self-efficacy beliefs regarding science teaching: A comparison of pre-service teachers in Turkey and the USA. Science Educator, 14, 31-40.

Canagarajah, S. (2007). Lingua franca English, multilingual communities, and acquisition. The Modern Language Journal, 91, 923-939.

Cogo, A. (2012). English as a Lingua Franca : Concepts, use and implications. ELT Journal, 66(1), 97-105.

Cohen, L., Manion, L. \& Morrison, K. (2007). Research methods in education (6th ed). New York, NY: Routledge.

Çelik, M. (2008). Pre-service EFL teachers' reported concerns and stress for practicum in Turkey. Education and Science, 33(150), 97-109.

De Graaff, R. and Housen, A. (2009). Investigating the Effects and Effectiveness of L2 Instruction. In M. H. Long \& Doughty C. J. (Eds), The Handbook of Language Teaching. Wiley-Blackwell, Oxford, UK.

De Jong, O., Ahtee, M., Goodwin, A. (1999). An international study of prospective teachers' initial teaching conceptions and concerns: the case of teaching 'combustion'. European Journal of Teacher Education , 22(1), 45-59.

Donaghue, H. (2003). An instrument to elicit teachers' beliefs and assumptions. ELT Journal, 57(4), 344-351.

Flynt, E. S., \& Brozo, W. (2010). Visual literacy and the content classroom: A question of now, not when. The Reading Teacher, 63(6), 526-528.

Griffiths, C. (2012). Focus on the teacher. ELT Journal, 66(4), 468-476.

Guillaume, A. M., \& Rudney, G. L. (1993). Student teachers' growth toward independence: An analysis of their changing concerns. Teaching and Teacher Education, 9(1), 65-80.

Jenkins, J. (2009). English as a lingua franca: interpretations and attitudes. World Englishes, $28(2), 200-7$. 
Karatas, S. (2010) The analysis of computer education and instructional technologies prospective teachers' mind maps relating to their profession (The Case of Gazi University) . Ahi Evran Üniversitesi Ĕ̆itim Fakültesi Dergisi,11(1), 159-173.

Kirkgoz, Y. (2005) English language teaching in Turkey: Challenges for the 21st century. In G . Braine (ed.) Teaching English to the World: History, Curriculum, and Practice (pp. 159175). Mahwah: Lawrence Erlbaum Associates.

Kirkgöz, Y. (2007). Language planning and implementation in Turkish primary schools. Current Issues in Language Planning, 8(2), 174-191

Krippendorff, K. (2004). Content Analysis: An Introduction to Its Methodology (2nd ed.). Thousand Oaks, CA: Sage

Kyriacou, C., \& Stephens, P. (1999). Student teachers' concerns during teaching practice. Evaluation and Research in Education, 13(1), 18-31.

Larsen-Freeman, D. (2000). Techniques and principles in language teaching (2nd ed). Oxford: Oxford University Press.

Lin, H., J. Gorrell, and J. Taylor. (2002). Influence of culture and education on US and Taiwan preservice teachers' efficacy beliefs. The Journal of Educational Research, 96(1), 3746.

Mau, R. Y. (1997). Concerns of student teachers: implications for improving the practicum. Asia-Pacific Journal of Teacher Education, 25(1), 53-65.

Prensky, M. (2001). Digital natives, digital Immigrants. On the Horizon, 9(5).

Robson, C. (1993). Real world research: A resource for social scientists and practitioerresearchers.Oxford: Blackwell Publishing.

Seidlhofer, B. (2004). Research perspectives on teaching English as a lingua franca. Annual Review of Applied Linguistics, 24, 209-239.

Seidlhofer, B. (2005). English as a lingua franca. ELT Journal, 59(4), 339-341.

Sowden, C. (2012). ELF on a mushroom: the overnight growth in English as a Lingua Franca. ELT Journal, 66(1), 89-96. doi:10.1093/elt/ccr024

Swennen, A., Jörg, T., \& Korthagen, F. (2004). Studying student teachers' concerns, combining image-based and more traditional research techniques. European Journal of Teacher Education, 27(3), 265-283.

Wyatt, M. (2011). Overcoming low self-efficacy beliefs in teaching English to young learners. International Journal of Qualitative Studies in Education, 26(2), 238-255.

Yayl1, L, \& Hasirci, S. (2009). Concerns of prospective teachers of Turkish on teaching The Journal of International Social Research, 2(9), 519-526. 